\title{
The Use of First Line Highly Active Anti-Retroviral Therapy (HAART) is Not Associated with Qtc Prolongation in HIV Patients
}

\author{
James Ogunmodede ${ }^{1}$, Philip Kolo ${ }^{1}$, Ibraheem Katibi ${ }^{1}$, Ayodele Omotoso ${ }^{1}$
}

\section{OPEN ACCESS}

Citation: James Ogunmodede, Philip Kolo, Ibraheem Katibi, Ayodele Omotoso. The Use of First Line Highly Active Anti-Retroviral Therapy (HAART) is Not Associated With Qtc Prolongation In Hiv Patients. Ethiop J Health Sci.2017;27(6):613. doi:http://dx.doi.org/10.4314/ejhs.v27i6.6

Received: May 24, 2017

Accepted: May 26, 2017

Published: November 1, 2017

Copyright: (C) 2017 OGUNMODEDE

J.A, et al . This is an open access article distributed under the terms of the Creative Commons Attribution License, which permits unrestricted use, distribution, and reproduction in any medium, provided the original author and source are credited.

Funding: Nil

Competing Interests: The authors

declare that this manuscript was approved

by all authors in its formand that no

competing interest exists

Affiliation and Correspondence:

${ }^{1}$ Department of Medicine, University of

Ilorin, Ilorin, Nigeria

*Email:

ayodeleogunmodede@yahoo.com

\section{ABSTRACT}

BACKGROUND: HAART has improved survival of HIV patients. Its contribution to the development of new cardiovascular abnormalities has generated much interest. This study aimed at determining the prevalence of QTc prolongation among HIV patients and determining the influence if any of the use of HAART on the QTc and on the risk of having QTc prolongation.

MATERIALS AND METHODS: One hundred and fifty HIV positive subjects comprising $76 \mathrm{HIV}$ positive subjects on HAART (Group A), 74 who were HAART- naïve (Group B), and 150 age and sex-matched healthy controls (Group C) were studied. All subjects had electrocardiography, and QTc duration was calculated.

RESULTS: Mean QTC was significantly different among the three groups $(P<0.001)$, highest in Group $B>$ Group $A>$ Group $C$. Frequency of QTc prolongation was highest in Group B (32\%)>, Group A (17.3\%)> Group C (4.7\%) (P<0.001). Mean QTc was significantly longer among patients with CD4 count $<200$ cells $/ \mathrm{mm}^{3}$ than among those with $>200$ cells $/ \mathrm{mm}^{3} 0.445 \pm 0.03 \mathrm{secs}$ vs $0.421 \pm 0.03$ secs $(P<0.001)$. QTc prolongation was commoner among individuals with CD4 count $<200$ cells $/ \mathrm{mm}^{3} 50 \%$ vs $20.5 \%$ $(P<0.001)$. On binary logistic regression, none of the HAART medications used by our patients was predictive of the occurrence of QTc prolongation.

CONCLUSION: The QTe is longer, and QTe prolongation occurs more frequently in HAART-naïve HIV patients than patients on HAART and healthy controls. None of the HAART medications used by our patients was predictive of the development of QTc prolongation.

KEYWORDS: QTc prolongation, HIVIAIDS, Highly Active AntiRetroviral Therapy (HAART)

\section{INTRODUCTION}

The Human Immunodeficiency Virus (HIV)/Acquired Immune Deficiency Syndrome (AIDS) pandemic is one of the most significant public health problems of the last four decades. Current concepts of its management have broadened from initial emphasis on 
opportunistic infections to the management of other organ-related complications $(1,2)$. This is because the introduction of the Highly Active Anti-Retroviral Therapy (HAART) has significantly improved the survival of HIV patients and enabled them to live long enough to develop other systemic complications of the disease (3). Cardiovascular involvement in HIV/AIDS was recognized in the early days of the pandemic (4) and a wide spectrum of cardiovascular abnormalities (5-9) including electrocardiographic abnormalities such as corrected QT interval (QTc) prolongation (10-12) have been reported.

The influence of HAART on the occurrence of QTc prolongation has also generated much interest with concerns that while contributing significantly to increased patient survival, HAART also increases patients' risk for cardiovascular diseases such as life-threatening arrhythmias, myocardial infarction and sudden cardiac death $(13,14)$. It is therefore important to assess important electrocardiographic parameters such as the QTc in HIV/AIDS patient on HAART in order to have a comprehensive understanding of their risk for cardiovascular events and to provide a rational basis for actions that will reduce the occurrence of cardiovascular morbidity and mortality. The objectives of this study were to determine the prevalence of QTc prolongation among HIV positive patients and to determine the influence if any of the use of HAART on the QTc and on the risk of having QTc prolongation.

\section{MATERIALS AND METHODS}

The study was a cross-sectional study carried out in the HIV clinics of the University of Ilorin Teaching Hospital (UITH), Ilorin, North central Nigeria. UITH is a large 500-bed tertiary healthcare facility whose HIV treatment service units receive referrals from about 5 neighbouring states of the federation.

Study population: The participants were HIV positive patients attending the HIV clinics of UITH and healthy age and sex-matched apparently healthy control subjects. The control subjects were recruited from among HIV negative blood donors in the UITH blood bank, volunteers from the Hospital and the surrounding community provided they satisfied the inclusion and exclusion criteria.

Inclusion criteria: Consenting HIV positive patients $\geq 18$ years of age with confirmed HIV positive results based on serological rapid tests done in UITH. The patients were receiving treatment in the HIV clinics of UITH.

Exclusion criteria: Patients with pre-existing systemic hypertension or other cardiac disease, arrhythmias or other conduction abnormalities, diabetes mellitus, or who were currently pregnant or in pueperium were excluded from the study. Patients with a history of current use of drugs known to affect the cardiovascular system or cause QTc prolongation or other drugs apart from antiretroviral drugs, as well as those with alcohol intake, cigarette smoking and electrolyte abnormalities were also excluded from the study.

Sample size calculation/sampling technique: The minimum sample size was calculated using the Fisher's statistical formula for estimating minimum sample size in health studies (15). The regional HIV prevalence rate of the study area which was $5.7 \%$ at the start of the study, and $95 \%$ confidence level, degree of accuracy of 0.05 and attrition rate of $10 \%$ were used in the calculation. The minimum sample size for the study was 82 . Hence, 164 HIV positive subjects were enrolled consecutively into the study and divided into two groups of 82 HIV positive subjects each: Group A comprising 82 patients already on HAART and Group B comprising 82 HIV positive subjects who were HAART-naïve. However, 14 of them fell short of the inclusion criteria. Thus, 150 HIV positive subjects comprising 76 HIV positive subjects on HAART and 74 who were HAARTnaïve were enrolled in to the study. One hundred and fifty age and sex-matched apparently healthy control subjects were also recruited from among HIV negative blood donors in the UITH blood bank, volunteers in the Hospital and in the surrounding community.

Study protocol: The presence of HIV infection in the patients was determined by a positive ELISA antibody test and Western blot confirmation. 
When Western blot was not available, diagnosis was based on two positive ELISA antibody tests using different kits and existence of at least two major and one minor signs of the disease in the absence of any known cause of immunosuppression. The CD4+ T lymphocyte cell count was measured by flow cytometry method using the DYNAL® T4 QUANT KIT, (made by DYNA Biotech, Oslo, Norway).

Electrocardiogram (ECG) recording was done on all study subjects using a Schiller ${ }^{\circledR}$ Cardiovit AT-10 ECG machine (SCHILLER AG Altgasse, Switzerland) operating at a speed of $25 \mathrm{~mm} / \mathrm{second}$ and sensitivity of $10 \mathrm{~mm} / \mathrm{mv}$ in accordance with the recommendations of the American Heart Association (AHA) on the standardization of leads and specification of instrument (16). Recordings were made after the individuals had rested for between 10-15 minutes and were interpreted by two different cardiologists among the authors. Lead II was used as the rhythm strip. The QT interval was measured in Lead II from the beginning of the QRS complex to the end of the T wave downslope. In the presence of a $U$ wave which joined the $\mathrm{T}$ wave, the QT interval was measured from the beginning of the QRS complex to the lowest point of the curve between the $\mathrm{T}$ and $\mathrm{U}$ waves. The QT interval was then corrected for heart rate using Bazett's formula (17). The upper limits of normal was set at $440 \mathrm{~ms}$ for men and $460 \mathrm{~ms}$ for women $(18,19)$. Clinical examination was carried out on all participants, and their age, sex, body mass index (BMI), blood pressure (BP), ECG heart rate (HR) and QTc were recorded. For HIV positive patients, the duration of HIV diagnosis, CD4 count, HAART medications used and duration of HAART use were also recorded. HIV viral load assay was not done for the patients because of non-availability of the facility at the study location.

Statistical analysis: The Statistical Package for the Social Sciences version 20 (SPSS inc., Chicago, IL, USA) was used to perform the statistical analysis. Continuous variables were expressed as mean \pm standard deviation. Categorical variables were expressed as percentages. Chi square was used to test significant differences between proportions and the independent $t$-test was used to compare means of two groups while one-way analysis of variance (ANOVA) was used to compare the means of three groups. Multiple pairwise comparisons between the groups were then performed using the Tukey test for post hoc analysis to determine where the significant difference impliedby ANOVA truly lies. Statistical significance was set at $P<0.05$. Binary logistic regression models were also generated to examine the relationship between the use of the various HAART medications and the occurrence or otherwise of prolonged QTc. "Prolonged QTc" was the dependent variable measured on a dichotomous scale "present" or "absent", and the different individual anti-retroviral medications were set as independent variables.

Ethical approval: Ethical approval was obtained from the Ethical Review Board of the University of Ilorin Teaching Hospital, Ilorin, Nigeria. All procedures followed were in accordance with the ethical standards of the responsible committee on human experimentation (institutional or regional) or with the Helsinki Declaration of the 1975, as revised in 1983.

\section{RESULTS}

The 150 HIV positive patients in the study consisted of 64 males $(42.7 \%$ ), and 86 females $(57.3 \%)$ were recruited consecutively for this study. The 76 Group A patients who were already on HAART comprised 32 males and 44 females while the seventy-four Group $B$ patients comprised 31 males and 43 females. The age and sex-matched 150 apparently healthy HIV negative controls comprised 63 males and 87 females (Group C). The mean ages of the three groups of subjects were statistically similar Group A- 38.7 \pm 8.8, Group B $-35.8 \pm 8.2$ and Group C - 40.1 \pm $16.9(\mathrm{P}=0.083)$. The mean $\mathrm{BMI}$ was significantly different among the 3 groups $(\mathrm{P}<0.001)$. Multiple pairwise comparisons showed that it was higher in Group $\mathrm{C}$ than in among Group A and also higher in Group C than in Group B subjects. The BMI was similar between both groups of HIV patients. The systolic BP was also significantly different among the three groups $(\mathrm{P}=0.011)$, it was higher 
among healthy controls (Group C) than Group B but similar between Groups A and B and between Groups B and C subjects. The mean QTc was significantly different among the three groups ( $\mathrm{P}$ $<0.001$ ); it was highest in Group B followed by Group A than Group C. Pairwise comparisons also revealed significant differences in all pairs of the Groups. The frequency of QTc prolongation was significantly different across the three groups; it was the highest in Group B (32\%), then Group A $(17.3 \%)$ and the lowest among healthy controls of Group C (4.7\%).

TABLE 1: Physical and Electrocardiographic Characteristics of Study Participants

\begin{tabular}{|c|c|c|c|c|c|}
\hline & $\begin{array}{c}\text { GROUP A HIV } \\
+\mathrm{Ve}, \\
\text { ON HAART } \\
\mathrm{N}=76\end{array}$ & $\begin{array}{c}\text { GROUP B } \\
\text { HIV +Ve, } \\
\text { HAART-Naïve } \\
\mathrm{N}=74\end{array}$ & $\begin{array}{c}\text { GROUP C } \\
\text { HIV-Ve } \\
\text { Control } \\
\mathrm{N}=150\end{array}$ & $\mathrm{P}$ value & $\begin{array}{l}\text { Tukey Post hoc } \\
\text { analysis (Where } \\
\text { significant } \\
\text { difference lies) }\end{array}$ \\
\hline Age (years) & $38.7 \pm 8.8$ & $35.8 \pm 8.2$ & $40.1 \pm 16.9$ & 0.083 & - \\
\hline $\begin{array}{l}\text { Gender } \\
\text { Male, n (\%) } \\
\text { Females n (\%) }\end{array}$ & $\begin{array}{l}32(42.7) \\
43(57.3)\end{array}$ & $\begin{array}{l}32(42.7) \\
43(57.3)\end{array}$ & $\begin{array}{l}64(42.7) \\
86(57.3)\end{array}$ & 1.0 & - \\
\hline BMI $\left(\mathrm{kg} / \mathrm{m}^{2}\right)$ & $21.7 \pm 4.9$ & $20.8 \pm 5.2$ & $25.1 \pm 4.7$ & $<0.001^{*}$ & $\mathrm{C}>\mathrm{A} ; \mathrm{C}>\mathrm{B}$ \\
\hline Heart rate (beats/min) & $85.1 \pm 17.5$ & $100.5 \pm 23.2$ & $82.9 \pm 19.6$ & $<0.001 *$ & $\mathrm{~B}>\mathrm{A}>\mathrm{C}$ \\
\hline Systolic BP (mmHg) & $113.9 \pm 13.1$ & $110.5 \pm 12.1$ & $115.3 \pm 9.4$ & $0.011 *$ & $\mathrm{C}>\mathrm{B}$ \\
\hline Diastolic BP (mmHg) & $73.9 \pm 8.9$ & $73 \pm 9.1$ & $74.1 \pm 7.7$ & 0.653 & - \\
\hline QTc $($ mean \pm SD $)$ & $0.424 \pm 0.03$ & $0.442 \pm 0.03$ & $0.421 \pm 0.04$ & $<0.001 *$ & $\mathrm{~B}>\mathrm{A}>\mathrm{C}$ \\
\hline Prolonged QTc (\%) & 17.3 & 32 & 4.7 & $<0.001 *$ & $B>A>C$ \\
\hline
\end{tabular}

HIV- Human Immunodeficiency Virus, BMI- Body Mass Index, BP- Blood pressure. Except otherwise stated, values are mean \pm standard deviation. *Significant

Gender comparisons among the HIV patients revealed that the QTc duration was significantly longer among male HIV patients on HAART than male HAARTnaïve patients, but similar among female patients in both groups of HIV positive patients. The mean QTc was, however, similar among female HIV patients (Table 2). The mean QTc was also significantly longer among patients with CD4 count $<200$ cells $/ \mathrm{mm}^{3}$ than among those with CD4 count $>200$ cells $/ \mathrm{mm}^{3} 0.445 \pm$
0.03 secs vs $0.421 \pm 0.03 \operatorname{secs}(\mathrm{P}<0.001)$. When the patients were classified according to the degree of immunosuppression into those with current CD4 count $<200$ cells $/ \mathrm{mm}^{3}$ (72 patients) and those with CD4 count $>200$ cells $/ \mathrm{mm}^{3}$ (78 patients), $50 \%$ of the individuals with CD4 count $<200$ cells $/ \mathrm{mm}^{3}$ had QTc prolongation while, among individuals with CD4 count $>200$ cells $/ \mathrm{mm}^{3}$, only $20.5 \%$ had QTc prolongation $(\mathrm{P}<0.001)$.

Table 2: QTc and CD4 Count of Hiv Patients.

\begin{tabular}{llll}
\hline & $\begin{array}{l}\text { Group A : HIV +ve on } \begin{array}{l}\text { Group B: HIV +ve } \\
\text { HAART } \\
\text { N=76 }\end{array} \\
\text { NAART-naïve } \\
\text { N=74 }\end{array}$ & \\
\hline QTc $(\mathrm{sec})$ & & & \\
Male & $0.417 \pm 0.03$ & $0.442 \pm 0.04$ & $0.04^{*}$ \\
Female & $0.430 \pm 0.03$ & $0.441 \pm 0.03$ & 0.085 \\
CD4 Count $\left(\right.$ cells $\left./ \mathrm{mm}^{3}\right)$ & $383.4 \pm 23.8$ & $252.7 \pm 23.5$ & $0.045^{*}$ \\
\hline
\end{tabular}

Except otherwise stated, values are mean \pm standard deviation *Significant

DOI: http://dx.doi.org/10.4314/ejhs.v27i6.6 
Table 3: Comparison of Qtc Duration between Patients with CD4 Count $<200$ Cells/ $\mathrm{Mm}^{3}$ and Those with CD4 Count >200 Cells/Mm ${ }^{3}$

\begin{tabular}{|c|c|c|c|}
\hline & $\begin{array}{l}\text { CD4 COUNT }<200 \\
\text { cells/mm } / \mathrm{mm}^{3}(\mathrm{~N}=72)\end{array}$ & $\begin{array}{l}\text { CD4 COUNT }>200 \\
\text { cells } / \mathrm{mm}^{3}(\mathrm{~N}=78)\end{array}$ & $P$ value \\
\hline QTc Duration (sec) & $0.445 \pm 0.03$ & $0.421 \pm 0.03$ & $<0.001 *$ \\
\hline QTc Prolongation (\%) & 50 & 20.5 & $<0.001^{*}$ \\
\hline
\end{tabular}

Except otherwise stated, values are mean \pm standard deviation *Significant

Binary logistic regression was performed to ascertain the effects of HAART medications on the likelihood that patients develop prolonged QTc. The logistic regression model fitted well at $\chi^{2}(7)=7.978$. The model correctly classified $83.3 \%$ of cases and explained only $12.2 \%$ (Nagelkerke $R^{2}$ ) of the variance in QTc prolongation due to individual HAART medication. None of the Nucleotide Reverse
Transcriptase Inhibitors on Non-Nucleotide Reverse Transcriptase Inhibitors (NNRTI) analysed in the model was predictive of the development of QTc prolongation as the outcome variable (Table 4). There were only two patients on PI, and these were automatically excluded from the model since the number was too few to make meaningful impact on the model.

Table 4: Prediction of the Development of Prolonged Qtc in HIV Patients by the Use of HAART Medications

\begin{tabular}{lllll}
\hline & B & Odds Ratio & 95\% CI & P value \\
\hline Nevirapine & .117 & 1.125 & $0.040-31.906$ & 0.945 \\
Efavirenz & -1.936 & .144 & $0.004-4.667$ & 0.275 \\
Lamivudine & 17.658 & 4.66 & $0.005-6.004$ & 1.000 \\
Stavudine & -.066 & .936 & $0.096-9.113$ & 0.954 \\
Tenofovir & 19.384 & 2.62 & $0.008-4.009$ & 1.000 \\
Emtricitabine & -0.672 & 0.511 & $0.113-2.303$ & 0.382 \\
Zidovudine & -0.161 & 0.851 & $0.088-8.272$ & 0.889 \\
\hline
\end{tabular}

HAART- Highly Active Anti-Retroviral Therapy B- Coefficient of binary logistic regression

\section{DISCUSSION}

The QTc is an electrocardiographic indicator of the duration of action potential in the ventricles representing the sum total of ventricular depolarization and repolarization. Its prolongation is indicative of increased risk of potentially fatal arrhythmias. Ventricular action potential is caused by the flow of ions across the myocyte cell membrane in two major currents which are: (1) the Inward depolarizing currents (which are: a. the sodium current (INa), b. the transient outward current (Ito) and c. the L (longlasting) -type calcium current also called $\mathrm{ICaL}$ ) and (2) the Outward currents (which are: a. the rapid component of the delayed rectifier potassium current $(\mathrm{IKr}), \mathbf{b}$. the slow component of the delayed rectifier potassium current (IKs), and c. the inward rectifier potassium current (IK1)) (20). In the general population, prolonged QTc is often predictive of lifethreatening arrhythmias, and adverse cardiovascular events and HIV/AIDS patients are not exempt from such risk (21).

The higher prevalence of QTc prolongation observed among HIV patients compared to healthy controls in our study has been variously reported by other researchers $(12,22-25)$. Various reasons that account for this include autonomic dysfunction (25) and other established predisposing factors to QTc prolongation such as female sex, drugs and electrolyte abnormalities (26).

Of the HIV patients in our study, the mean CD4 count was higher among patients who were on HAART than among those who were HAART-naïve. Our study found that QTc was the longest and the prevalence of QTc prolongation occurred most frequently in HAART-naïve patients followed by patients on

DOI: http://dx.doi.org/10.4314/ejhs.v27i6.6 
HAART with healthy control subjects having the lowest values of these parameters. Similar observations were reported by Ogunmola et al who suggested a relationship between CD4 count and QTc duration (22). This relationship is highlighted in our patients when their QTc duration and QTc prolongation prevalences were analysed with respect to the degree of immunosuppression as measured by the CD4 count. Patients with profound immunosuppression with CD4 count $<200$ cells $/ \mathrm{mm}^{3}$ had a longer QTc duration and higher prevalence of QTc prolongation than those with a higher CD4 count. This same trend was also reported by Gili et al (27) who found that a low CD4 count was associated with QTc prolongation independent of HAART. Nordin et al (10) also reported a similar trend in the association between CD4 count and QTc duration in their observation of an inverse correlation between CD4 count and QTc prolongation among HIV patients in their studied cohort. The relationship between the CD4 count and QTc prolongation may be mediated through the role of heightened inflammation and serum levels of inflammatory mediators which occur in patients with low CD4 count thereby predisposing them to QTc prolongation. In advanced HIV disease, depletion of the CD4 cells leads to the activation of CD8 killer T-cells which mediate persistent immune dysfunction and inflammation $(28,29)$.

The impact of inflammation on the occurrence of QTc prolongation has been elucidated by Lanzzerini et al (20). Inflammation is a cardinal feature of HIV infection and myocarditis, which occurs frequently in HIV (and which can be sub-clinical) is a known cause of QTc prolongation (30). The key inflammatory mediators of QTc prolongation identified by various workers include cytokines (particularly TNF $\alpha$, IL-6, IL-1 $\beta$ ), which may affect the myocardium either directly, by modulating specific ion channels critically involved in action potential development, and indirectly, by increasing central nervous system sympathetic drive on the heart (31-33).

The evaluation of the relationship between the use of HAART, and the prevalence of QTc prolongation has yielded different observations from different workers over time. Evaluating the possible effect of HAART on QTc is important because the number of patients accessing HAART in resource-poor settings such as ours has increased dramatically over the past 20 years. Indeed, from 2001 to 2005 , the number of persons receiving antiretroviral therapy in low-and middle-income countries increased 15- fold from 240,000 to about 1.3 million (34), and a further $84 \%$ increase in access also occurred between 2010-2015 (35).

In assessing the impact of individual antiretroviral drug on QTc prolongation, our study observed that QTc prolongation in HIV patients was independent of all the individual anti-retroviral drugs taken by them. We assessed four nucleoside reverse transcriptase inhibitors (stavudine, lamivudine, zidovudine, emtricitabine), a nucleotide reverse transcriptase inhibitor (tenofovir) and two nonnucleoside reverse transcriptase inhibitors (NNRTI) (nevirapine and efavirenz) in logistic regression model, and none of them was predictive of the occurrence of QTc prolongation. These are the commonest drugs used in combination for the care of HIV patients in the study centre. Our observation is similar to that of Owens et al (36) and Chinello et al (37) who also found that Nucleoside reverse transcriptase inhibitors and Nucleotide reverse transcriptase inhibitors were not associated with QTc prolongation. However, unlike our findings, these authors reported an association between efavirenz (an NNRTI) and nelfinavir (a PI). Only two of our patients were on a PI and were excluded from the regression analysis. The effect of PI on escalating cardiovascular risk factors such as dyslipidemia and coronary calcification has been reported by Meng et al (13). In our centre, PIs are used as part of second-line HAART regimens when initial treatment with nucleoside reverse transcriptase inhibitors, nucleotide reverse transcriptase inhibitors and NNRTIs fail. Hence, very few of our patients were on them. Anson et al have demonstrated that QTc prolongation caused by some PIs; namely, amprenavir, indinavir, lopinavir, nelfinavir, ritonavir and saquinavir results from their suppression of the human ether-a-go-go-related gene (hERG) ion channel which mediates the repolarising inward potassium current, IKr, which is one of the dominant ionic currents involved in the generation of cardiac action potential (38). The blockage of HERG channel and IKr induced by PIs, leads to a direct reduction in repolarisation reserve, prolongation of the duration of action potential and a concurrent rise in susceptibility to acquired long QT syndrome and torsade de pointes (38).

Our study suggests that Nucleoside reverse transcriptase inhibitors and Nucleotide reverse transcriptase inhibitors used among HIV patients in our centre would not account for the QTc prolongation found among them compared to healthy controls. Possible pathogenetic factors may include well-known factors such as the effects of inflammation (discussed earlier) and oxidative stress on the myocardium (39). It

DOI: http://dx.doi.org/10.4314/ejhs.v27i6.6 
is possible to deduce that when patients commence HAART and their viral load drops, inflammatory processes mediated by the HIV subside, and these mechanisms which promote QTc prolongation are mitigated. Thus, the shorter QTc is observed among patients on HAART.

Though our study may be limited by its crosssectional approach, it offers another perspective to an important scientific discussion. A prospective study will no doubt be needed to evaluate the relationship between HAART use and QTc prolongation, especially to examine the effect of PIs.

In conclusion, QTc prolongation observed among our patients appears to be independent of their HAART use. We believe that it is important for physicians to consider the risk of QTc prolongation while managing HIV-infected persons particularly those yet to commence HAART. This will be useful as a strategy to reduce their overall risk of developing adverse cardiovascular outcomes.

\section{REFERENCES}

1. Kabwe L, Lakhi S, Kalinichenko S, Mulenga L. Prevalence of subclinical Cardiovascular Disease in healthy HIV infected patients at the University Teaching Hospital in Lusaka, Zambia. Medical Journal of Zambia 2016;43( 1): 12-23.

2. Nzuobontane D Blackett KN, Kuaban C. Cardiac involvement in HIV infected people in Yaounde, Cameroon. Postgrad Med J 2002; 78:678-681.

3. Olusegun-Joseph DA, Ajuluchukwu JNA, Mbakwem AC, Oke DA, Okubadejo NU, Okany CC. Echocardiographic patterns in treatment-naïve HIV-positive patients in Lagos, South-west Nigeria. Cardiovasc J Afr. 2012; 23(8): e1-e6.

4. Reichert CM, O'Leary TJ, Levens DL, Simrell CR, Macher AM. Autopsy pathology in acquired immune deficiency syndrome. Am $J$ Pathol 1983;112:357-82.

5. Uwanuruochi K, Onwubere BJ, Anisiuba BC. Echocardiographic study of left ventricular function in HIV-infected Nigerians. West African Journal of Radiology 2015;22(1):27-31.

6. Paisible AL, Chang CC, So-Armah KA, Butt AA, Leaf DA, Budoff $M$, et al. HIV Infection, Cardiovascular Disease Risk Factor Profile, and Risk for Acute Myocardial Infarction. J Acquir Immune Defic Syndr. 2015;68(2):209-216.

7. Sani MU, Okeahialam BN. Epidemiology and Pathogenesis of Human Immunodeficiency Virus Related heart disease: A review. Niger J. Med 2005;14(3):255-260.
8. Tseng ZH, Secemsky EA, Dowdy D, Vittinghoff E, Moyers B, Wong JK, et al. Sudden Cardiac Death in Patients With Human Immunodeficiency Virus Infection. JACC 2012;59(21):1891-6.

9. Manga P, McCutcheon K, Tsabedze N, Vachiat A, Zachariah D. HIV and Nonischemic Heart Disease. JACC 2017;69(1):83-91.

10. Nordin C, Kohli A, Beca S, Zaharia V, Grant T, Leider J, Marantz P. Importance of hepatitis C coinfection in the development of QT prolongation in HIV-infected patients. J Electrocardiol 2006; 39: 199-205.

11. Soliman EZ, Prineas RJ, Roediger MP, Duprez DA, Boccara F, Boesecke C, et al. Prevalence and prognostic significance of ECG abnormalities in HIV-infected patients: results from the Strategies for Management of Antiretroviral Therapy study. Journal of Electrocardiology 2011;44(6):779-85.

12. Njoku PO, Ejim EC, Anisiuba BC, Ike SO, Onwubere BJC. Cardiovascular Journal of Africa Electrocardiographic findings in a cross-sectional study of human immunodeficiency virus (HIV) patients in Enugu, South-East Nigeria. Cardiovascular Journal of Africa 2016;27(4):252.

13. Meng Q, Lima JA, Lai H, Vlahov D, Celentano DD, Strathdee SA, et al. Coronary artery calcification, atherogenic lipid changes, and increased erythrocyte volume in black injection drug users infected with human immunodeficiency virus-1 treated with protease inhibitors. Am Heart J. 2002;144(4):642-48.

14. Neumann T. HIV and cardiac disease. In: Hoffmann C, Rockstroh J, Kamps BS. Editors. HIV Medicine 2007. 15th ed. Paris: Flying Publishers;2007. p.617-26.

15. Araoye MO. Sample Size Determination. In: Research Methodology with Statistics for Health and Social Sciences. Araoye MO, Ed. Ilorin (Nigeria): Nathadex Publishers; 2004. pp 115-120.

16. American Heart Assocciation (AHA) Committee report : Recommendations for standardization of leads and specification for instruments in electrocardiography and vectocardiography. Circulation 1975;52:11-20.

17. Bazett HC. An analysis of the time-relations of 122.electrocardiograms. Heart 1920;7:353-370.

18. Goldberg RJ, Bengtson J, Chen ZY, Anderson KM, Locati E, Levy D. Duration of the QT interval and total and cardiovascular mortality in healthy persons (The Framingham Heart Study experience). Am J Cardiol 1991;67:55-8. 
19. Bednar MM, Harrigan EP, Anziano RJ, Camm AJ, Ruskin JN. The QT interval. Prog Cardiovasc Dis 2001;43 5 Suppl 1:1-45.

20. Lazzerini PE, Capecchi PL, Laghi-Pasini F. Long QT syndrome: an emerging role for inflammation and immunity. Frontiers of Cardiovascular Medicine 2015; 2(26):1-17.

21. Kocheril AG, Bokhari SA, Batsford WP, Sinusas AJ. Long QTc and torsades de pointes in human immunodeficiency virus disease. Pacing Clin Electrophysiol 1997;20: 2810-6.

22. Ogunmola JO, Oladosu YO, Olamoyegun MA. QTc interval prolongation in HIV-negative versus HIV-positive subjects with or without antiretroviral drugs. Annals of African Medicine 2015;14(4):169.

23. Sani MU, Okeahialam BN. QTc interval prolongation in patients with HIV and AIDS. $J$ Natl Med Assoc. 2005;97:1657-61.

24. Reinsch N, Buhr C, Krings P, Kaelsch H, Neuhaus $\mathrm{K}$, Wieneke $\mathrm{H}$, Erbel $\mathrm{R}$, Neumann $\mathrm{T}$ and the German Heart Failure Network. Prevalence and Risk Factors of Prolonged QTc Interval in HIVInfected Patients: Results of the HIV-HEART Study. HIV Clin Trials 2009;10(4):261-8.

25. Villa A, Foresti V, Confalonieri F. Autonomic neuropathy and prolongation of QT interval in human immunodeficiency virus infection. Clin Auton Res 1995; 5:48-52.

26. van Noord C, Eijgelsheim M, Stricker BHC. Drugand non-drug-associated QT interval prolongation. Br J Clin Pharmacol. 2010 Jul; 70(1): 16-23.

27. Gili S, Mancone M, Ballocca F, Marra WG, Calcagno A, D'ettorre G, et al. Prevalence and predictors of long corrected QT interval in HIVpositive patients: a multicenter study. Journal of Cardiovascular Medicine 2017. Published online ahead of print. Available at: http://journals.lww.com/jcardiovascularmedicine/A bstract/publishahead/Prevalence_and_predictors_o f_long_corrected_QT.98664.aspx Accessed on March 17,2017.

28. Fernandez S, Lim A, French M. Immune activation and the pathogenesis of HIV disease: implications for therapy. Journal of HIV therapy 2009;14(3):52.

29. Paiardini M, Müller-Trutwin M. HIV-associated chronic immune activation. Immunological reviews. 2013;254(1):78-101.
30. Ramamurthy S, Talwar KK, Goswami KC, Shrivastava S, Chopra P, Broor S, et al. Clinical profile of biopsy proven idiopathic myocarditis. Int J Cardiol 1993; 41:225-32.

31. Wang J, Wang $\mathrm{H}$, Zhang $\mathrm{Y}$, Gao H, Nattel S, Wang Z. Impairment of HERG $\mathrm{K}(+)$ channel function by tumor necrosis factor-alpha: role of reactive oxygen species as a mediator. $J$ Biol Chem 2004;279:13289-92.

32. Li YH, Rozanski GJ. Effects of human recombinant interleukin-1 on electrical properties of guinea pig ventricular cells. Cardiovasc Res 1993;27:525-30.

33. Hagiwara Y, Miyoshi S, Fukuda K, Nishiyama N, Ikegami Y,Tanimoto K,et al. SHP2-mediated signaling cascade through gp130 is essential for LIF-dependent ICaL, $[\mathrm{Ca} 2+] \mathrm{i}$ transient, and APD increase in cardiomyocytes. J Mol Cell Cardiol 2007;43:710-6.

34. UNAIDS. 2006 report on the global AIDS epidemic: executive summary/UNAIDS. May 2006. Available at: http://data.unaids.org/pub/ GlobalReport/2006/2006_GR-

ExecutiveSummary_en.pdf. Accessed 8 January 2007.

35. UNAIDS. AIDS by the Numbers 2015. Available at:

http://www.unaids.org/en/resources/documents/20

15/AIDS_by_the_numbers_2015. Accessed on February 3, 2017.

36. Owens RC, Nolic TD. Reply to Petrosillo and Chinello. Clinical Infectious Diseases 2007; 44:1389-91.

37. Chinello P, Lisena FP, Angeletti C, Boumis E, Papetti SF, Petrosillo N. Role of antiretroviral treatment in prolonging QTc interval in HIVpositive patients. Journal of Infection 2007;54:597602.

38. Anson BD, Weaver JG, Ackerman MJ, Akinsete O, Henry K, January CT et al. Blockade of HERG channels by HIV protease inhibitors. Lancet 2005; 365: 682-686.

39. Hare JM. The Dilated, Restrictive, and Infiltrative Cardiomyopathies. In: Libby P, Bonow RO, Mann DL, Zipes DP. Editors. Braunwald's Heart Disease. A textbook of cardiovascular medicine. 8th Ed.Philadelphia: Saunders; 2008: pp 17391760 .

DOI: http://dx.doi.org/10.4314/ejhs.v27i6.6 